\title{
Prediction of Standardized Tests and English Competence for Saudi Medical Students' Performance in an Introductory Physics Course
}

\author{
Abdulaziz Althewini \\ ${ }^{1}$ Assistant professor at King Saud bin Abdulaziz University for Health Sciences and King Abdullah International \\ Medical Research Center, Saudi Arabia
}

Correspondence: Abdulaziz Althewini, P.O. Box 22490 - Mail Code 3124, Riyadh 11426, Saudi Arabia. E-mail: thewinia@ksau-hs.edu.sa

Received: December 5, 2019 Accepted: January 13, 2020 Online Published: February 5, 2020

doi:10.5539/ijel.v10n2p153 URL: https://doi.org/10.5539/ijel.v10n2p153

\begin{abstract}
The following study tested the relationship between admission criteria and college students' performance in an introductory physics course. For this study, I analyzed the performance of 250 students based on two college admission standardized tests (i.e., General Aptitude Test (GAT), Scholastic Achievement Admission Test (SAAT)), and English competence performance (i.e., average English course grades and reading and communication proficiency test). Based on this analysis, GAT and SAAT, along with English competence, are significant individual predictors for students' performance in physics. Reading proficiency tests were the best individual predictors in simple linear regression analysis with $19.6 \%$ variance. The combined methods, with multivariate regression analysis, explained only $29.3 \%$ of physics course grade variance. This low variance of Saudi admission criteria for a single physics course should motivate Saudi policymakers to conduct a national study that includes an increased number of participants. Through such a national study, more evidence-based conclusions regarding the college admission system can be made to improve the admission process for Saudi students.
\end{abstract}

Keywords: standardized tests, English competence, physics education, predictive validity, medical education, college admission

\section{Introduction}

The academic community of high education views Saudi standardized tests and English competence as indicators for selecting high school students who may perform well in college. However, such assumptions are not tested and evaluated adequately to assure whether these two admission components can predict students' college performance. When students apply to college, they are required to take the General Aptitude Test (GAT) and Scholastic Achievement Admission Test (SAAT). Besides, their scores in both standardized tests are combined with their high school GPA to create a collective score for college administrators to make informed admission decisions. GAT is a general aptitude test created by the national Saudi center of measurement (QIYAS) and is aimed to test students' analytical skills and their learning ability. SAAT is a scholastic achievement admission test, also created by QIYAS, with an emphasis on students' comprehension of principles in biology, chemistry, physics, and mathematics taught in the courses of high school. As for English competence, there are questions on whether students' performance in English as a second language courses and English proficiency tests can predict students' college success in general and specifically at science subjects.

In this study, I statistically aim to evaluate whether standardized tests and English competence can predict medical students' performance in an introductory physics course during their first year of college. This physics course is selected specifically because there is an inquiry among physics teachers on whether students' English proficiency level does help them to perform well in the physics course or otherwise it does not have a significant impact on their performance. In addition, the teachers are interested to see whether there is a connection between students' fresh background of GAT, SAAT, and high school and their performance in the physics course, so they could contemplate on whether to manipulate and adapt their curriculum and teaching method. This study has educational value for college policymakers to assure the college admission system is fair. Especially, in light of recent literature and global policy discussions regarding college admission systems and the predictive power of standardized tests, this study contributes to local Saudi attempts to evaluate the predictive validity of admission 
criteria for college students' academic performance.

Admission to medical colleges has been a sensitive issue discussed globally (Schwartz, 2004; Roberts \& Prideaux, 2010; McManus et al., 2011; Prideaux et al., 2011). There are different ways to measure students' readiness for medical colleges (Evans \& Wen, 2007; McManus et al., 2003; Groves et al., 2007). Benbassat et al. (2007) state that medical school admission is based primarily on cognitive achievements within the context of students' social qualities and skills. These qualities could include over 70 personality traits highlighted by research (Albanese et al., 2003).

Some colleges have been interested in nonacademic personal qualities that have seen as vital for mastering health science knowledge and skills (Searle et al., 2003; Sefcik et al., 2009; Jessee et al., 2006). The University of Adelaide, for instance, created a written examination concerning reasoning and interaction skills that includes a structured oral assessment (Turnbull et al., 2003). However, measuring students' reasoning skills separately is found to be less predictive of academic performance than measuring students' cognitive knowledge (McManus et al., 2005a, b).

Other colleges prefer to employ a combination of prior academic criteria, such as students' GPA, reasoning and decision-making tests, and interviews (Julian, 2005; Peskun et al., 2007). Among these colleges, there are major differences in how admission committees use each criterion (Parry et al., 2006). However, when these criteria are combined, the greater predictive validity of students' performance in college is possible (Ferguson et al., 2003). Thus, many colleges use a holistic approach to evaluate a wide range of criteria to predict students' college performance.

That said, students' grade point average (GPA) is often seen as more reliable to predict students' college performance (Ferguson et al., 2002; McManus et al., 2003; Coates, 2008; Wright \& Bradley, 2010). Wilkinson et al. (2008) concluded that GPA is strongly correlated with students' performance in medical colleges. Such a relationship is stronger in the first year and begins to be less predictive as students continue their studies at an institution. However, the importance of students' GPA is often based on college GPAs, where students are required to finish four years of college before attending medical school. In contrast, students in Saudi Arabia can graduate from high school and directly apply to different health sciences colleges, including medicine.

Contributing to current discussions regarding the relationships between admission test, language competence, and college performance, this study complements global discussions regarding admission criteria for medical students by taking a micro approach to analyze the relationship between Saudi admission criteria and students' performance in one single course, physics. Moreover, the study provides essential information for local educators to evaluate the validity of admission criteria within the context of other available data.

\section{Research Questions}

This study analyzed the predictive validity of GAT, SAAT, and English competence for predicting students' performance in physics courses, which is a prerequisite for medical study. The research questions for the study were the following:

- Do GAT, SAAT, English average, reading proficiency test, and communication proficiency test individually predict students' performance in physics? If so, which one is the best and weakest predictor?

- When GAT, SAAT, English courses average, reading proficiency test, and communication proficiency test are combined as predictors in multivariate regression analysis, what is their variance of predicting students' performance in physics?

\section{Research Method}

It is vital to clarify some background information on this study, explaining its context, the focus on physics courses, and how English competence is measured.

The study participants are 250 male freshmen students at a Saudi university. During their first semester, students take low intermediate English courses, and then they take science courses in the second semester, including biology, chemistry, and physics. Based on their performance and cumulative GPA in both semesters, they compete for several medical majors, including medicine, dentistry, pharmacy, and applied medical sciences. Each major has limited spots and requires different college GPA requirements.

Students, after taking the physics course, should be able to explain the kinematics and dynamics of moving objects, physics of matter, mechanics of waves, basic principles of electricity and magnetism, electromagnetism and electromagnetic waves, principles of optics, in addition to other modern physics concepts with a focus on atomic and nuclear applications in the medical field. Students attended their physics lectures four hours a week, in a 
large lecture hall, and took two midterm exams and a final, with English as the primary language for instruction.

I measured students' English competence in two ways during this study. Since students take intensive English courses in the first semester that cover topics such as grammar, reading, and communication before taking a physics course, I calculated and included the average of students' English scores. Moreover, students were asked to take English reading and communication proficiency tests. These tests were designed by a number of English language teachers and reviewed.

The reading test was created to determine whether students can read and understand academic texts. The tests measure students' skills in referencing and inferencing and whether they can interpret and link information presented in a reading. The test also evaluates students' abilities to locate main ideas and supporting evidences in a reading passage, apply reading and critical thinking strategies to move beyond the literal meaning of a passage, and differentiate opinions from facts. Also, the reading test assesses students' comprehension of diagrams and illustrations and the ability to separate cause from effect while evaluating students' mastery of vocabulary.

The communication proficiency test measures students' execution of different rhetorical styles such as definition and argumentation essays. The test evaluates their ability to restate and review information and focuses on whether students are capable to predict and create conclusions based on a specific text. Equally important, the communication proficiency test is used to analyze students' ability to understand rhetorical structure within a reading passage and assesses students' ability to create a topic sentence and paragraph that includes supporting details.

In summary, the study used both reading and communication proficiency tests along with the average English score as predictions for students' performance in physics courses.

The data in this study included five predictive (independent) variables (i.e., GAT, SAAT, English courses average, reading tests, and communication tests) and one dependent variable: physics grade. They were received from the students and then were analyzed through simple linear regression and multivariate regression analysis with SPSS program.

\section{Results}

For the first question, in order to look at each predictor individually, the study used simple linear regression. Table 1 shows the variance of each predictor and its significance for physics course grades. The reading test is the best individual predictor, explaining 19.6\% variance of the dependent variable. English average explains 14.7\% of the outcome variance. GAT and SAAT predict $9.4 \%$ and $7.9 \%$ outcome variance, whereas communication tests are the weakest predictor ( $\mathrm{R}$-square $=7.2 \%$ ). The combined model is stronger than individual models $-29.3 \%$ $\mathrm{R}$-square as in Table 2, using multivariate regression analysis.

Table 1. Individual prediction summary for students' physics grade

\begin{tabular}{lllllllll}
\hline Model & Variable & $\mathrm{R}$ & $\mathrm{R}$ Square & $\begin{array}{l}\text { Adjusted R } \\
\text { Square }\end{array}$ & $\begin{array}{l}\text { Regression } \\
\text { Coefficient }\end{array}$ & $\begin{array}{l}\text { Std. } \\
\text { Error }\end{array}$ & $\mathrm{T}$ & $\begin{array}{l}\text { Coefficient } \\
\text {-value }\end{array}$ \\
\hline 1 & GAT & 0.306 & .094 & .090 & 0.051 & 0.010 & 5.100 & 0.000 \\
2 & SAAT & 0.281 & .079 & .075 & 0.047 & 0.010 & 4.700 & 0.000 \\
3 & English_average & 0.383 & .147 & .143 & 0.729 & 0.116 & 6.284 & 0.000 \\
4 & Reading_test & 0.443 & .196 & .193 & 0.416 & 0.054 & 7.704 & 0.000 \\
5 & Communication_test & 0.268 & .072 & .068 & 0.292 & 0.068 & 4.294 & 0.000 \\
\hline
\end{tabular}

Table 2. Combined prediction model summary

\begin{tabular}{llllll}
\hline Model & Variable & R & R Square & Adjusted R Square & Std. Error of The Estimate \\
\hline 1 & CT, GAT, SAAT, ENGL, RT & 0.542 & .293 & .278 & 0.736 \\
\hline
\end{tabular}

Note. Predictors: (Constant). Communication test (CT), SAAT, GAT, English average (ENGL), Reading test (RT).

Regarding the coefficients, GAT and reading test have zero p-value, as shown in Table 3. Thus, they are the best predictors of Physics course grade. English average is also significant with $\mathrm{p}<0.05$. Based on the coefficients table, the regression equation for predicting students' performance in physics is: $-2.902+0.034 * \mathrm{GAT}+$ $0.019 *$ SAAT $+0.327 *$ English average $+0.277 *$ reading test $-0.031 *$ communication test. 
Table 3. Coefficient of each predictor

\begin{tabular}{|c|c|c|c|c|c|c|c|}
\hline \multirow{2}{*}{\multicolumn{2}{|c|}{ Model }} & \multicolumn{2}{|c|}{ Unstandardized Coefficients } & \multirow{2}{*}{$\begin{array}{l}\text { Standardized Coefficients } \\
\text { Beta }\end{array}$} & \multirow[t]{2}{*}{$\mathrm{t}$} & \multirow[t]{2}{*}{ Sig. } & \multirow[t]{2}{*}{$\mathrm{P}$} \\
\hline & & $\mathrm{B}$ & Std. Error & & & & \\
\hline \multirow[t]{6}{*}{1} & (Constant) & -2.902 & 1.056 & & -2.748 & .006 & \\
\hline & GAT & .034 & .010 & .201 & 3.257 & .001 & $\mathrm{P}<0.0005$ \\
\hline & SAAT & .019 & .010 & .115 & 1.853 & .065 & \\
\hline & English_average & .327 & .128 & .172 & 2.562 & .011 & $\mathrm{P}<0.05$ \\
\hline & Reading_test & .277 & .074 & .296 & 3.755 & .000 & $\mathrm{P}<0.0005$ \\
\hline & Communication_test & -.031 & .081 & -.028 & -0.379 & .705 & \\
\hline
\end{tabular}

Note. a. Dependent Variable: physics grade.

\section{Discussion}

The results show that all of the independent variables are significant individual predictors for students' performance in the physics course. Reading test and average English scores are the best predictors, whereas GAT, SAAT, and communication test have weaker predictive values. Students' English competence does play an important role in their mastery of physic content since course material and lectures are delivered in English. Thus, students, regardless of their excellence in science, must have a solid, basic understanding of English. Without knowing English, students tend to fail in the course instead of mastering course content. Although physics has its coherent and special English scientific terms, students' mastery of general English content does help to overcome jargon.

Moreover, reading skills are especially important since it is the best predictor overall. This result implies that students' ability to read critically, gather information, and create conclusions is highly valuable for students' success in physics courses and ultimately to become medical students. However, although reading tests do highly predict success in physics courses, communication tests have a much lower value. While students' writing skills may predict students' performance in physics, students are not required to write and talk in forms of oral presentation and group work since their course format consists mostly of lectures that use a teacher-centered approach. Their communication skills are not as important compared to reading skills. However, physics teachers could improve students' learning of physics by creating classroom activities that improve students' communication skills in the science field.

GAT and SAAT, as national standardized tests, were the worst predictors of students' performance in physics courses. Standardized admission tests do predict some students' performance in one single science course. However, even with the heavy use of standardized admission tests within the global academic medical community, more institutions are becoming interested in nonacademic personal qualities to make admission decisions (Searle et al., 2003). Some colleges already created a written examination to determine reasoning skills to help with selecting students with a higher level of reasoning and analytical thinking (Turnbull et al., 2003). However, measuring students' reasoning skills separately is less predictive of academic performance compared to measuring students' cognitive knowledge (McManus et al., 2005a, b). Given these results, using GAT as a local Saudi test for reasoning skills does predict a little and should be combined with other admission criteria.

The combined model of independent variables explains $29.3 \%$ R-square of physics variance. The model explains a moderate relationship between the predictors and physics course grades. However, the predictive variance is still low, indicating that almost $70 \%$ of the variance is unexplained. The results speak to the difficulty to predict students' performance in physics classes and the need to analyze more relative independent predictors. This realization is common among various global studies on the predictive power of admission criteria concerned about students' progress in college. Others have also shown that a large percentage of variance for this predictive relationship is unexplained (Callahan et al., 2010; James et al., 2010; Lynch et al., 2009; Evans \& Wen, 2007). Similar to this study, which resulted in predictors lacking explanation, some systematic reviews of these predictive studies report that unexplained variance may extend to $70 \%$ (Ferguson et al., 2002).

Moving forward, this study does have limitations. It used Saudi medical male students as the primary source of data to examine students' performance. Also, only one course was used to create results for the study. It also does not take into account other predictors for students' performance such as family income and socio-economic status. Lastly, the study focuses on introductory college-level physics course. Future studies about the predictors of success for aspiring medical studies within Saudi Arabia ought to consider these limitations. 


\section{Conclusion}

Saudi admission criteria of GAT and SAAT, along with English competence tests, are significant individual predictors for students' performance in physic classes. Reading tests rank to be the best predictor, illustrating the importance for students to have strong reading skills. However, based on the results of this study, I recommend that physics teachers incorporate more opportunities for students to improve their communication skills and explain verbally, and in writing, how students understand course content. This study also illustrates the need to have a valid and strong model of admission criteria since the combined model explains only $29.3 \%$ of physics grade variance. These results can help Saudi policymakers to conduct a more robust national study, with large number of participants, to analyze and improve the current admission criteria.

\section{References}

Albanese, M. A., Snow, M. H., Skochelak, S. E., Huggett, K. N., \& Farrell, P. M. (2003). Assessing personal qualities in medical school admissions. Academic Medicine, 78(3), 313-321. https://doi.org/10.1097/00001888-200303000-00016

Benbassat, J., \& Baumal, R. (2007). Uncertainties in the selection of applicants for medical school. Advances in Health Sciences Education, 12(4), 509-521. https://doi.org/10.1007/s10459-007-9076-0

Callahan, C. A., Hojat, M., Veloski, J., Erdmann, J. B., \& Gonnella, J. S. (2010). The predictive validity of three versions of the MCAT in relation to performance in medical school, residency, and licensing examinations: a longitudinal study of 36 classes of Jefferson Medical College. Academic Medicine, 85(6), 980-987. https://doi.org/10.1097/ACM.0b013e3181cece3d

Coates, H. (2008). Establishing the criterion validity of the graduate medical school admissions test (GAMSAT). Medical Education, 42(10), 999-1006. https://doi.org/10.1111/j.1365-2923.2008.03154.x

Evans, P., \& Wen, F. K. (2007). Does the medical college admission test predict global academic performance in osteopathic medical school? Journal of the American Osteopathic Association, 107(4), 157.

Ferguson, E., James, D., \& Madeley, L. (2002). Factors associated with success in medical school: systematic review of the literature. British Medical Journal, 324(7343), 952-957. https://doi.org/10.1136/bmj.324.7343.952

Ferguson, E., McManus, I. C., James, D., O’Hehir, F., \& Sanders, A. (2003). Pilot study of the roles of personality, references, and personal statements in relation to performance over the five years of a medical degree. British Medical Journal, 326(7386), 429-432. https://doi.org/10.1136/bmj.326.7386.429

Groves, M. A., Gordon, J., \& Ryan, G. (2007). Entry tests for graduate medical programs: is it time to re-think? Medical Journal of Australia, 186(9), 486. https://doi.org/10.5694/j.1326-5377.2007.tb01013.x

James, D., Yates, J., \& Nicholson, S. (2010). Comparison of a level and UKCAT performance in students applying to UK medical and dental schools in 2006: Cohort study. British Medical Journal, 349, c478. https://doi.org/10.1136/bmj.c478

Jessee, S. A., O'Neil, P. N., \& Dosch, R. O. (2006). Matching student personality types and learning preferences to teaching methodologies. Journal of Dental Education, 70, 644-651.

Julian, E. R. (2005). Validity of the Medical College Admission Test for predicting medical school performance. Academic Medicine, 80(10), 910-917. https://doi.org/10.1097/00001888-200510000-00010

Lynch, B., MacKenzie, R., Dowell, J., Cleland, J., \& Prescott, G. (2009). Does the UKCAT predict Year 1 performance in medical school? Medical Education, 43(12), 1203-1209. https://doi.org/10.1111/j.1365-2923.2009.03535.x

McManus, I. C., Ferguson, E., Wakeford, R., Powis, D., \& James, D. (2011). Predictive validity of the Biomedical Admissions Test: an evaluation and case study. Medical Teacher, 33(1), 53-57. https://doi.org/10.3109/0142159X.2010.525267

McManus, I. C., Iqbal, S., Chandrarajan, A., Ferguson, E., \& Leaviss, J. (2005). Unhappiness and dissatisfaction in doctors cannot be predicted by selectors from medical school application forms: A prospective, longitudinal study. BMC Medical Education, 5(1), 38. https://doi.org/10.1186/1472-6920-5-38

McManus, I. C., Powis, D. A., Wakeford, R., Ferguson, E., James, D., \& Richards, P. (2005). Intellectual aptitude tests and A levels for selecting UK school leaver entrants for medical school. British Medical Journal, 331(7516), 555-559. https://doi.org/10.1136/bmj.331.7516.555 
McManus, I. C., Smithers, E., Partridge, P., Keeling, A., \& Fleming, P. R. (2003). A levels and intelligence as predictors of medical careers in UK doctors: 20-year prospective study. British Medical Journal, 327(7407), 139-142. https://doi.org/10.1136/bmj.327.7407.139

Parry, J., Mathers, J., Stevens, A., Parsons, A., Lilford, R., Spurgeon, P., \& Thomas, H. (2006). Admissions processes for five-year medical courses at English schools. British Medical Journal, 332(7548), 1005-1009. https://doi.org/10.1136/bmj.38768.590174.55

Peskun, C., Detsky, A., \& Shandling, M. (2007). Effectiveness of medical school admissions criteria in predicting residency ranking four years later. Medical Education, 41(1), 57-64. https://doi.org/10.1111/j.1365-2929.2006.02647.x

Prideaux, D., Roberts, C., Eva, K., Centeno, A., Mccrorie, P., Mcmanus, C., ... Wilkinson, D. (2011). Assessment for selection for the health care professions and specialty training: consensus statement and recommendations from the Ottawa 2010 Conference. Medical Teacher, 33(3), 215-223. https://doi.org/10.3109/0142159X.2011.551560

Roberts, C., \& Prideaux, D. (2010). Selection for medical schools: re - imaging as an international discourse. Medical Education, 44(11), 1054-1056. https://doi.org/10.1111/j.1365-2923.2010.03852.x

Searle, J., \& McHarg, J. (2003). Selection for medical school: just pick the right students and the rest is easy! Medical Education, 37(5), 458-463. https://doi.org/10.1046/j.1365-2923.2003.01496.x

Sefcik, D. J., Prerost, F. J., \& Arbet, S. E. (2009). Personality types and performance on aptitude and achievement tests: Implications for osteopathic medical education. Journal of American Osteopathic Association, 109(6), 296-301.

Schwartz, S. (2004). Fair admissions to higher education: recommendations for good practice. London: Higher Education Steering Group.

Turnbull, D., Buckley, P., Robinson, J. S., Mather, G., Leahy, C., \& Marley, J. (2003). Increasing the evidence base for selection for undergraduate medicine: four case studies investigating process and interim outcomes. Medical Education, 37(12), 1115-1120. https://doi.org/10.1111/j.1365-2923.2003.01716.x

Wilkinson, D., Zhang, J., Byrne, G. J., Luke, H., Ozolins, I. Z., Parker, M. H., \& Peterson, R. F. (2008). Medical school selection criteria and the prediction of academic performance. Medical Journal of Australia, 189(4), 235. https://doi.org/10.5694/j.1326-5377.2008.tb01998.x

Wright, S. R., \& Bradley, P. M. (2010). Has the UK Clinical Aptitude Test improved medical student selection? Medical Education, 44(11), 1069-1076. https://doi.org/10.1111/j.1365-2923.2010.03792.x

\section{Copyrights}

Copyright for this article is retained by the author, with first publication rights granted to the journal.

This is an open-access article distributed under the terms and conditions of the Creative Commons Attribution license (http://creativecommons.org/licenses/by/4.0/). 